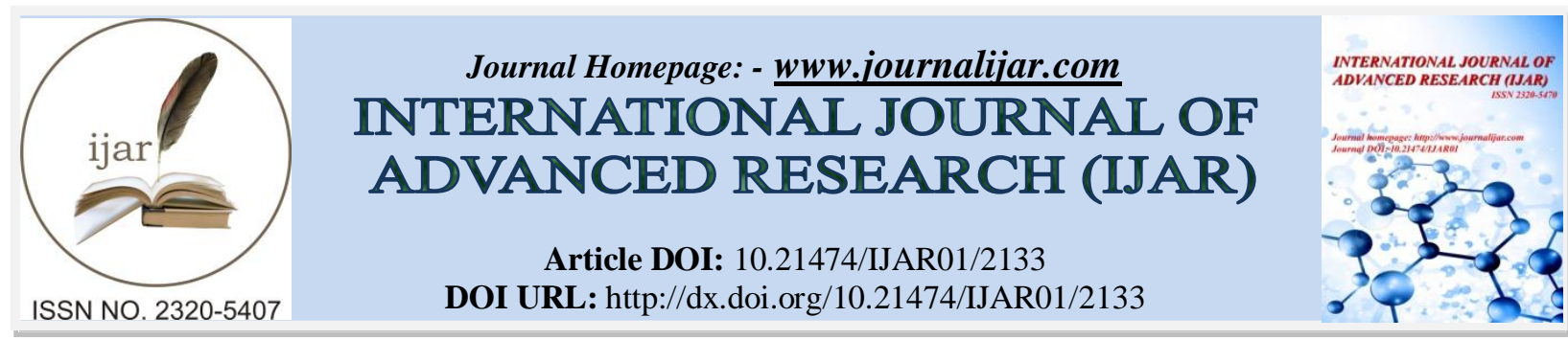

RESEARCH ARTICLE

\title{
OPTIMIZING EXTRACTION CONDITIONS OF MORINGA OLEIFERA LAM LEAF FOR PERCENT YIELD, TOTAL PHENOLICS CONTENT, TOTAL FLAVONOIDS CONTENT AND TOTAL RADICAL SCAVENGING ACTIVITY.
}

\section{Harith Jameel Mahdi ${ }^{1}$, Emad Muthana Yousif ${ }^{2}$, Nurzalina Abdul Karim Khan ${ }^{3}$, Roziahanim Mahmud ${ }^{4}$, Vikneswaran A/L Murugaiyah ${ }^{5}$ and Mohd Zaini Bin Asmawi ${ }^{6}$.}

1. Discipline of Pharmaceutical Technology, School of pharmaceutical Sciences, USM, Malaysia.

2. Discipline of Pharmaceutical Chemistry, School of pharmaceutical Sciences, USM, Malaysia.

3. Assoc. Prof. Dr., Discipline of Pharmaceutical Technology, School of pharmaceutical Sciences, USM, Malaysia.

4. Assoc. Prof. Dr., Discipline of Pharmaceutical Chemistry, School of pharmaceutical Sciences, USM, Malaysia.

5. Assoc. Prof. Dr., Discipline of Pharmacology, School of pharmaceutical Sciences, USM, Malaysia.

6. Prof. Dr., Discipline of Pharmacology, School of pharmaceutical Sciences, USM, Malaysia.

\section{Manuscript Info}

\section{Manuscript History}

Received: 25 September 2016

Final Accepted: 27 October 2016

Published: November 2016

Key words:-

Extraction, Percent yield, Total Phenolics content, Total flavonoids content and Total radical scavenging activity.

\section{Abstract}

Moringa oleifera Lam has been used in traditional medicines since long time worldwide. Phenolics and flavonoids, as major phytoconstituents, assumed to be responsible for many of the biological activities. The quality and quantity of such phytoconstituents highly effected by extraction conditions. To obtain highest possible quality and quantity extract, the effects of different extraction solvents, extraction temperatures, maceration times and best ratio of dried powdered leaves to extraction solvent on percent yield, TPC, TFC and total radical scavenging activity were tested. The results reveals a significant effect of temperature on quantity and quality of extract. The effects of maceration time were directly related to temperature of extraction, while the ratio of dried powdered leaves to extraction solvent had a non-significant effect on both quantity and quality of the extract. Extraction of $M$. oleifera leaf with amiable and placid conditions was recommended for high quality and bioactive extract.

Copy Right, IJAR, 2016,. All rights reserved.

\section{Introduction:-}

Consumption of herbs as nutritive food and/or medicines has played an important role in nearly every culture in Asia, Africa, Europe and the Americas, wherein natural products have been an integral part of most ancient traditional medicine systems such as those of Chinese, Ayurvedic and Egyptian. Nowadays, plants have assumed expanded uses in modern health care programmes as natural source of bioactive compounds, treatment of malnutrition, and drug template amongst drug discovery researchers in search for alternative sources of drugs (Bhagyasri, et al., 2015). As many as 3.4 billion people in the developing world depend on plant-based traditional medicines and dietary supplements (Kumar, et al., 2013; Arora and Kaur, 2013). This represented more than 80 percent of the developed world population, who relied mainly on traditional medicine for their primary health care due to poverty, lack of access to modern medicine and awareness of side effects (Isitua et al., 2015). Usage of herbal 
medicine is based on the hypothesis that medicinal plants contain natural substances that can promote health and ameliorate illness. These plant-produced natural substances or phytochemicals such as phenolics, flavonoids, alkaloids, tannins, glycosidal aglycones and vitamins were considered pharmacologically active constituents that can be responsible for a diverse bioactivity (Tan et al., 2013).

Moringa oleifera Lam is one such important plant with a very wide use in almost all traditional medicine references such as the Greek, Egyptian, Roman and Indian with writings dating back as far as 150 AD (Zaku et al., 2015). M. oleifera Lam is the most widely cultivated species of a mono-generic family, the Moringaceae, that is native to the sub-Himalayan tracts of India and Pakistan, and now inhabitant in tropical and sub-tropical regions worldwide (AlOwaisi et al., 2014; Agbogidi and Ilondu, 2012; Varma 2016). Moringa was known in 82 countries by 210 different names in over 200 languages as the horseradish tree, drumstick tree, benzolive tree, moonga, mulangay, nébéday, saijhan, sajna tree (Leone et al., 2015). This evergreen rapidly-growing tree is widely used as a nutritive herb, food (leaf and pods), industry, and almost, each plant part possesses valuable pharmacological activities. Traditionally, it is used for the treatment of various diseases, malnutrition and health conditions such as antimicrobial, antihyperlipidemic, anticancer, antiulcer, antidiabetic, analgesic, antihypertension, antifertility, anticonvulsant, asthma, hepatoprotective, arthritis, rheumatism, prostrate problems, sexual virility, erectile dysfunction, syphilis and many others (Maheshwari et al., 2014; Nath et al., 2015; Kumar, V., et al., 2013; Ganatra et al., 2012; Kesharwani et al., 2014; Jaiswal et al., 2009). The apparently wide range of therapeutic activity of M. oleifera was attributed to the variety of active phytochemicals present in its different plant parts namely the vitamins, carotenoids, polyphenol, phenolic acids, flavonoids, alkaloids, glucosinolates, isothiocyanates, tannins, saponins, oxalates and phytates (Gopalakrishnan et al., 2016; Leone et al., 2015).

The leaf part of $M$. oleifera are considered to give high nutrient content of the plant, rich source of vitamins, phenolics, flavonoids, essential amino acids, proteins, and minerals and exhibited strong antioxidant activity, often attributed to the plant vitamins and phenolic compounds (Coppin et al., 2013; Muazu and Suleiman, 2014; Sankhalkar and Vernekar, 2016; Jayanthi et al., 2015).

To be reliable, effective and trustable by consumers, natural products should be first extracted, isolated, identified the active constituent(s), clinically tested and then formulated as standardized pharmaceutical dosage form. In view of that, extraction is the first and the most essential and critical step in the isolation, purification, identification and standardization of active phytoconstituent(s) from plant materials (Do et al., 2014). An appropriate extraction method should be used to collect the bioactive phytochemicals with high-quality yield regarding reproducibility, applicability, environment safety issue and cost (Varma, 2016). Theoretically, optimal extraction method should be simple, rapid, economical and applicable to a large scale industry. The main challenge of an extraction process is to offer the maximum yield of substances with the highest quality, concentration and bioactivity power of the target compounds (Tan et al., 2013) among a wide spectrum of the plant constituents where as many as 200,000 different compounds although not every constituent occurs in every species (Gullberg et al., 2004).

Many techniques have been developed to extract active constituents, such as conventional solvent extraction, microwave-assisted, ultrasound-assisted and supercritical fluid extraction, among which solvent extraction (solidliquid and liquid-liquid extraction techniques) is the most commonly used, and has proven to be a reliable and efficient method (Jung, 2014). In spite of extensive uses, many factors, such as solvent composition, time of extraction, temperature, solid-to-liquid ratio and particle size, may drastically influence the efficiency of solid-liquid extraction (Dent et al., 2013).

The objective of this study was to evaluate the effects of various extraction solvents, temperatures, ratio of solvent to solid plant material and maceration time on the plant extraction yield, total phenolics content, total flavonoids content and free radical scavenging activity towards 2,2-diphenylpicrylhydrazyl (DPPH) of M. oleifera dried leaf extract under various conditions. A single factor experiments approach (a one-factor-at-a-time) was used, in which only one factor is varied at a time while all others are kept constant. Such approach is able to provide fundamental information on the ranges for an optimum extraction set of parameter for the extraction of phytochemicals from the plant material. The study will help improve extraction of phenolics, flavonoids and other antioxidants from $M$. oleifera Lam leaf and promote better utilization of the extract as a standardized medicinal plant. 


\section{Materials and methods:- Chemicals and Equipments:-}

All chemicals and solvents used were of analytical reagent (AR) grade. Ethanol 95\%, Methanol, Toluene, 1Butanol, Aluminum chloride $\left(\mathrm{AlCl}_{3}\right)$, Sodium carbonate $\left(\mathrm{Na}_{2} \mathrm{CO}_{3}\right)$ and Ascorbic acid, were obtained from Fisher Scientific, Selangor, Malaysia. 1,1-diphenyl-2-picrylhydrazyl (DPPH) and Quercetin reference standard ( $\geq 98 \%$ purity) were obtained from Sigma-Aldrech, USA. Gallic acid $\left(\mathrm{C}_{7} \mathrm{H}_{6} \mathrm{O}_{5}\right)(98 \%$ purity) was obtained from Acros Organics, Belgium, USA. TLC Silica gel $60 \mathrm{~F}_{254}$, Folin-Ciocalteu reagent Merck KGaA, Darmstadt, Germany. Water bath and drying oven, MEMMERT, Germany; Rotary evaporator, EYEL4, China; UV-Visible spectrophotometer BIOCHROM LIBRA S11, Cambridge, England; PERKIN ELMER, Lambda 25 UV/VIS Spectrophotometer, USA. Deionized distilled water (reverse osmosis water) used for the analysis was purified by MILLI-Q Millipore water purification system (Millipore Corporation, Billerica, USA).

\section{Plant Materials:-}

A fresh leaves of M. oleifera Lam were collected from Butter worth area, Penang, Malaysia in November, 2015. These were authenticated and a voucher specimen (voucher No. 11626 ) preserved in the herbarium, School of Biological Sciences, Universiti Sains Malaysia (USM). 2.3. Preparation of M. oleifera leaf for extraction

The fresh leaves were cleaned out first with tape water to remove dusts and dirt then washed with distilled water twice. The cleaned leaves were dried in oven at $45^{\circ} \mathrm{C}$ for 3 to 5 days to get a constant weight dry mass. The dry leaves then powdered using grinding mill to a particle size of about $0.5 \mathrm{~mm}$. The powdered dried leaves then packed in polyethylene bag and stored in sealed container at dark cool room until use.

\section{Extraction of dried powdered M. oleifera leaf:-}

In the first stage of the study, the dried powdered leaves was extracted with either $95 \%$ ethanol, $50 \%$ ethanol or water by maceration with (1:10) dried powdered leaves to extraction solvent ratio at $45{ }^{\circ} \mathrm{C} \pm 2$ for $48 \mathrm{~h}$. One hundred gram of powdered leaves was placed in a glass flask, $1000 \mathrm{ml}$ of either extraction solvents was added, the flask covered with aluminium foil and transferred into water bath with occasional shake. At the end of maceration period the extracts were filtered using Whatman No.1 filter paper, concentrated by rotary evaporator to about $10 \%$ of the original volume. The marc was re -extracted by the same process and solvent for three times and the concentrated extracts were combined together. Thereafter, the concentrated extracts were dried in drying oven at $45^{\circ} \mathrm{C} \pm 2$ until we get a constant weight of dry mass. The collected dried extracts were used to determine the best extraction solvent. In the second stage of the study, the powdered leaves was extracted by maceration in the selected extraction solvent at different extraction conditions in which only one parameter was changed each step - A different extraction temperature i.e. $35,45,55,65^{\circ} \mathrm{C}$, different dried powdered leaves to extraction solvent ratio i.e. 1:10, 1:5 and 1:2.5 ratio and different maceration time i.e. 24, 48 and 72 hours were tested to evaluate the effects of each parameter on the quantity and quality of the collected extract. After the end of maceration time of each step the extract was filtered, concentrated, dried, weighed and stored frozen until use for determination of TPC, TFC and total scavenging activity.

\section{TLC profile of extract:-}

The TLC profile of the three extracts was used to evaluate the efficiency of extraction solvent (in addition to other tests) by roughly estimating the number of phytochemicals in each extract. After a preliminary TLC runs with various mobile phases, a mobile phase consisting of toluene : 1-butanol :methanol (9.5:0.5:0.5) was used which reveal best separation of components. Sample was prepared $(2 \mathrm{mg} / \mathrm{ml})$ in methanol and applied in the form of band (5 $\times 0.45 \mathrm{~mm}$ ). Plate was developed up to the distance of $10 \mathrm{~cm}$ from bottom, air dried and visualized at $365 \mathrm{~nm}$.

\section{Percent yield:-}

The percent yield of extract was calculated after obtaining a constant dried weight with respect to weight of used dry powdered leaves using the following equation:

$$
\% \text { yield }=\frac{\text { Weight of dry extract }}{\text { Weight of powdered leaves }} \times 100
$$

The percent yield was used to estimate the efficiency of extraction conditions. 


\section{Total Phenolics Content (TPC):-}

Total phenolics content was determined by the Folin-Ciocalteu method as described by Vongsak et al., (2013) with minor modification. Two hundred $\mu \mathrm{l}$ of $1 \mathrm{mg} / \mathrm{ml}$ extract in methanol was mixed with $0.5 \mathrm{ml}$ of dilute folin-Ciocalteu reagent (1:10 with deionized distilled water), mix well and stand for $5 \mathrm{~min}$; then, $0.8 \mathrm{ml}$ of $7.5 \%(\mathrm{w} / \mathrm{v})$ sodium carbonate $\left(\mathrm{Na}_{2} \mathrm{CO}_{3}\right)$ in distilled water was added, allowed to stand for $30 \mathrm{~min}$ at room temperature and in dark place for colour development with occasional shake. Absorbance was then measured using spectrophotometer at $765 \mathrm{~nm}$ against a blank ( $200 \mu \mathrm{l}$ extract solution, $0.5 \mathrm{ml}$ methanol and $0.8 \mathrm{ml}$ distilled water). A series of Gallic acid solutions ( 5 to $320 \mu \mathrm{g} / \mathrm{ml}$ ) in methanol were prepared and used as a reference to interpolate the concentration of the phenolics content in the plant extract sample. The TPCs were determined using linear regression equation obtained from the standard plot of Gallic acid. The content of total phenolic compounds was calculated as mean \pm standard deviation $(\mathrm{SD})(\mathrm{n}=3)$ and expressed as $\mathrm{g}$ Gallic acid equivalent (GAE) /100g extract.

\section{Total flavonoids content (TFC):-}

The total flavonoids content was determined using the modified method of Al-Owaisi et al., 2014. Five ml of 2\% (w/v) Aluminium chloride $\left(\mathrm{AlCl}_{3}\right)$ in methanol was added to $5 \mathrm{ml}$ of M. oleifera extract $(0.5 \mathrm{mg} / \mathrm{ml})$, mixed well and incubated in dark place for $10 \mathrm{~min}$ at room temperature. Absorbance was then measured using spectrophotometer at $415 \mathrm{~nm}$ against a blank ( $\mathrm{AlCl}_{3}$ and methanol). A series of quercetin solutions $(1.95$ to $125 \mu \mathrm{g} / \mathrm{ml})$ in methanol were prepared and used as a reference to interpolate the concentration of the flavonoids content of $M$. oleifera extract sample. The content of total flavonoids compounds was calculated as mean \pm standard deviation $(\mathrm{SD})(\mathrm{n}=3)$ and expressed in g quercetin equivalent $(\mathrm{QE}) / 100 \mathrm{~g}$ extract.

Total radical scavenging activity:-

Total radical scavenging capacity of $M$. oleifera leaf extracts was determined by 1,1-diphenyl-2-picrylhydrazyl (DPPH) method described by Pyrzynska and Pękal (2013) with minor modification. A stock solution of 1mM DPPH in methanol was prepared in amber flask wrapped with aluminium foil and stored at $-20{ }^{\circ} \mathrm{C}$. The working solution of $0.152 \mathrm{mM}$ was prepared by taking $15.2 \mathrm{ml}$ into a $100 \mathrm{ml}$ amber volumetric flask and complete the volume to 100 with methanol. A series dilution of M. oleifera extract to obtain a solutions with a concentration ranging (1.95 to 500 $\mu \mathrm{g} / \mathrm{ml})$. A series dilution of ascorbic acid solution was prepared to obtain a solutions with a concentration ranging ( 7.8125 to $1000 \mu \mathrm{g} / \mathrm{ml}$ ) and used as reference. After the incubation period, the absorbance of each solution of $M$. oleifera extract and ascorbic acid was measured using a spectrophotometer at $517 \mathrm{~nm}$ against a blank $(1.5 \mathrm{ml}$ $\mathrm{DPPH}+750 \mu \mathrm{l}$ methanol). The ability to scavenge DPPH radical was calculated as percent inhibition using the following equation:

$$
\% \text { inhibition }=\frac{\mathrm{Ab}-\mathrm{At}}{\mathrm{Ab}} \times 100
$$

Were $\mathrm{Ab}$ is the absorbance of blank and $\mathrm{At}$ is the absorbance of test sample. The $\mathrm{IC}_{50}$ value, the concentration of sample required for $50 \%$ scavenging of the DPPH free radical, was determined from the curve of percent scavenging plotted against the concentration. Each determination was done in triplicate, and the mean \pm standard deviation of $\mathrm{IC}_{50}$ value was calculated. All results were expressed in $\mathrm{g}$ ascorbic acid equivalent/ $100 \mathrm{~g}$ of dry extract (g AAE/100g extract).

\section{Data analysis:-}

The results were reported as mean \pm standard deviation (SD) $(n=3)$. The average contents of total phenolics, total flavonoids and DPPH radical scavenging activity of the extracts prepared by the different extraction conditions were statistically investigated using one-way analysis of variance (ANOVA) followed by Tukey post hoc multiple comparisons with least significant difference (LSD) by SPSS for Windows 20.0. A statistical probability ( $p$ value) less than 0.05 indicated a statistically significant difference between groups.

\section{Results:-}

The percent yields for the $95 \%$ ethanol, 50\% ethanol and water extracts which extracted at $45 \mathrm{C}$ for $48 \mathrm{~h}$ and 1: 10 dried powdered leaves to extraction solvent ratio were $25.022,38.196$ and $37.838 \%$ respectively (Table 1 ). Since our concern is extraction of bioactive phyto-constituents like polyphenolics and antioxidants, the selection of extraction solvent was based on other testing parameters and the percent yield will be a comparing parameter of extraction conditions within the same extraction solvent. 
Table 1:- The $\%$ yield, TPC, TFC and total scavenging activity of $95 \%$ ethanol, $50 \%$ ethanol and water extract.

\begin{tabular}{|l|l|l|l|l|}
\hline Solvent & \% yield & $\begin{array}{l}\text { TPC } \\
\text { g GAE/100 g extract }\end{array}$ & $\begin{array}{l}\text { TFC } \\
\text { g QE/100 g extract }\end{array}$ & $\begin{array}{l}\text { DPPH } \\
\text { g AAE/100 g extract }\end{array}$ \\
\hline $95 \%$ ethanol & 25.022 & $28.800 \pm 0.76$ & $4.425 \pm 0.31$ & $7.302 \pm 1.43$ \\
\hline $50 \%$ ethanol & 38.196 & $3.525 \pm 0.11$ & $1.206 \pm 0.66$ & $7.310 \pm 2.04$ \\
\hline Water & 37.838 & $1.836 \pm 1.03$ & $0.804 \pm 0.58$ & $6.367 \pm 1.98$ \\
\hline
\end{tabular}

GAE: Gallic acid equivalent, QE: Quercetin equivalent and AAE: Ascorbic acid equivalent.

The TLC profile of the three extracts (95\% ethanol, 50\% ethanol and water) clearly illustrated that $95 \%$ ethanol had extracted more phytoconstituents than other extraction solvents (Fig. 1). Taking in our account the results of preliminary runs of TPC, TFC, DPPH and TLC profile, 95\% ethanol was selected as extraction solvent in next stage of the study for testing the effects of different extraction condition on quantity and quality of extract.

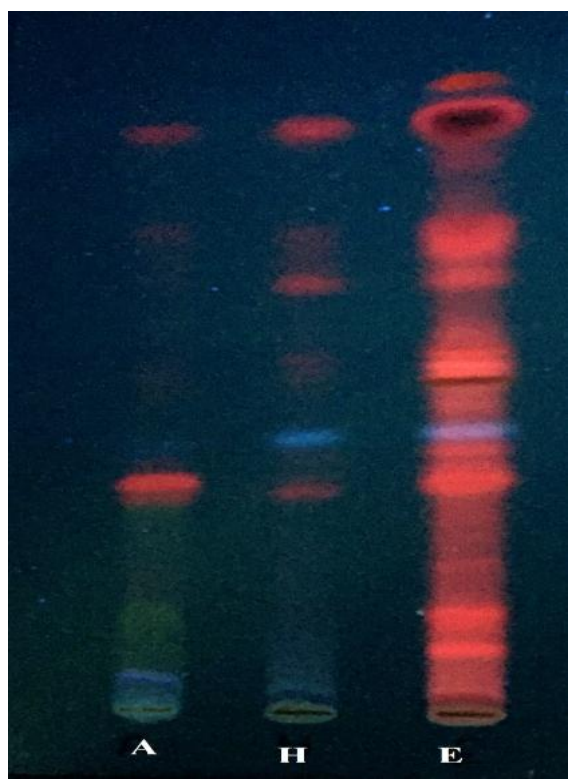

Fig. 1:- TLC profile of three Moringa leaf extracts. A: water extract, H: $50 \%$ ethanol and E: $95 \%$ ethanol.

\section{Effects of temperature on extract quantity and quality:-}

Analysis of the collected data (Table 2) apparently shows a significant and direct relationship between temperature and percent yield in all extraction conditions. The extraction yield increased as the temperature of extraction increased and highest percent yield at $65^{\circ} \mathrm{C}$ (Fig. 2). An obvious effect of temperature on TPC was noted in all dried powdered leaves to extraction solvent ratio and 48 and $72 \mathrm{~h}$ maceration time ( $p$ value 0.001 to 0.014$)$ with highest value was at $45^{\circ} \mathrm{C}$ ( $p$ value 0.002$)$ except for $24 \mathrm{~h}$ maceration time in which the highest value was at $55^{\circ} \mathrm{C}(\mathrm{Fig} .3)$. For TFC, the increase in temperature leads to increase in TFC value ( $p$ value 0.001 to 0.021 ) except for $65^{\circ} \mathrm{C}$ with maceration time longer than $24 \mathrm{~h}$ in which the value start to decrease. The highest TFC value was at temperature $55^{\circ} \mathrm{C}$ (Fig. 4). The total radical scavenging activity appear to be more susceptible to temperature regardless dried powdered leaves to extraction solvent ratio and maceration time ( $p$ value 0.001 to 0.003 ) with highest scavenging activity at temperature $45^{\circ} \mathrm{C}$ (Fig. 5). This behavior may be due to sensitivity and instability of vitamins like $\alpha-$ Tocopherol and Ascorbic acid and pro-vitamin like $\beta$-Carotene (which is largely responsible for anti-oxidant activity) to high temperature. 
Table 2:- Percent yield, TPC, TFC and total radical scavenging activity of 95\% ethanol extract of $M$. oleifera leaf at different extraction conditions.

\begin{tabular}{|c|c|c|c|c|c|c|}
\hline $\begin{array}{l}\text { Temperature } \\
\left({ }^{\circ} \mathrm{C}\right)\end{array}$ & Ratio & $\begin{array}{l}\text { Maceration } \\
\text { Time (h) }\end{array}$ & $\%$ Yield & $\begin{array}{l}\text { TPC } \\
\text { g GAE/100 g } \\
\text { extract }\end{array}$ & $\begin{array}{l}\text { TFC } \\
\text { g Q/100g } \\
\text { extract }\end{array}$ & $\begin{array}{l}\text { DPPH } \\
\text { g AAE } / 100 \quad \text { g } \\
\text { extract }\end{array}$ \\
\hline \multirow[t]{9}{*}{20} & $1: 10$ & 24 & 19.214 & 20.463 & 2.721 & 2.907 \\
\hline & $1: 10$ & 48 & 19.878 & 21.829 & 3.265 & 3.236 \\
\hline & $1: 10$ & 72 & 20.115 & 22.017 & 3.742 & 3.829 \\
\hline & $1: 5$ & 24 & 18.395 & 19.908 & 2.663 & 2.934 \\
\hline & $1: 5$ & 48 & 19.735 & 22.488 & 3.189 & 3.078 \\
\hline & $1: 5$ & 72 & 20.046 & 22.720 & 3.377 & 3.488 \\
\hline & $1: 2.5$ & 24 & 18.605 & 20.040 & 2.495 & 2.962 \\
\hline & $1: 2.5$ & 48 & 19.246 & 21.030 & 2.805 & 3.203 \\
\hline & $1: 2.5$ & 72 & 19.612 & 21.605 & 3.046 & 3.305 \\
\hline \multirow{9}{*}{45} & $1: 10$ & 24 & 22.676 & 23.103 & 3.664 & 6.541 \\
\hline & $1: 10$ & 48 & 25.022 & 28.800 & 4.425 & 7.302 \\
\hline & $1: 10$ & 72 & 25.455 & 29.183 & 4.570 & 8.050 \\
\hline & $1: 5$ & 24 & 23.189 & 23.327 & 3.355 & 6.407 \\
\hline & $1: 5$ & 48 & 23.765 & 28.640 & 4.287 & 7.658 \\
\hline & $1: 5$ & 72 & 24.834 & 28.859 & 4.408 & 8.262 \\
\hline & $1: 2.5$ & 24 & 22.813 & 25.476 & 3.066 & 6.825 \\
\hline & $1: 2.5$ & 48 & 24.324 & 28.700 & 3.851 & 6.977 \\
\hline & $1: 2.5$ & 72 & 25.206 & 28.776 & 4.265 & 7.849 \\
\hline \multirow{9}{*}{55} & $1: 10$ & 24 & 23.743 & 30.146 & 4.055 & 7.136 \\
\hline & $1: 10$ & 48 & 24.336 & 28.092 & 4.723 & 5.924 \\
\hline & $1: 10$ & 72 & 26.689 & 26.954 & 4.850 & 5.064 \\
\hline & $1: 5$ & 24 & 24.246 & 26.163 & 3.903 & 5.708 \\
\hline & $1: 5$ & 48 & 24.838 & 25.812 & 4.525 & 4.550 \\
\hline & $1: 5$ & 72 & 26.401 & 24.495 & 4.416 & 3.376 \\
\hline & $1: 2.5$ & 24 & 23.089 & 24.985 & 3.770 & 5.413 \\
\hline & $1: 2.5$ & 48 & 25.190 & 24.267 & 4.300 & 4.550 \\
\hline & $1: 2.5$ & 72 & 26.375 & 22.896 & 4.598 & 3.412 \\
\hline \multirow{9}{*}{65} & $1: 10$ & 24 & 25.233 & 29.031 & 4.160 & 4.983 \\
\hline & $1: 10$ & 48 & 26.105 & 25.614 & 4.315 & 3.651 \\
\hline & $1: 10$ & 72 & 28.301 & 18.096 & 3.840 & 3.270 \\
\hline & $1: 5$ & 24 & 24.097 & 27.123 & 4.285 & 4.906 \\
\hline & $1: 5$ & 48 & 26.311 & 21.238 & 4.150 & 3.048 \\
\hline & $1: 5$ & 72 & 27.220 & 14.519 & 3.655 & 2.638 \\
\hline & $1: 2.5$ & 24 & 24.064 & 23.601 & 3.945 & 4.301 \\
\hline & $1: 2.5$ & 48 & 25.766 & 21.639 & 3.440 & 2.854 \\
\hline & $1: 2.5$ & 72 & 28.141 & 16.928 & 2.975 & 2.552 \\
\hline
\end{tabular}

AAE: ascorbic acid equivalent, GAE: gallic acid equivalent and QE: quercetin equivalent. 


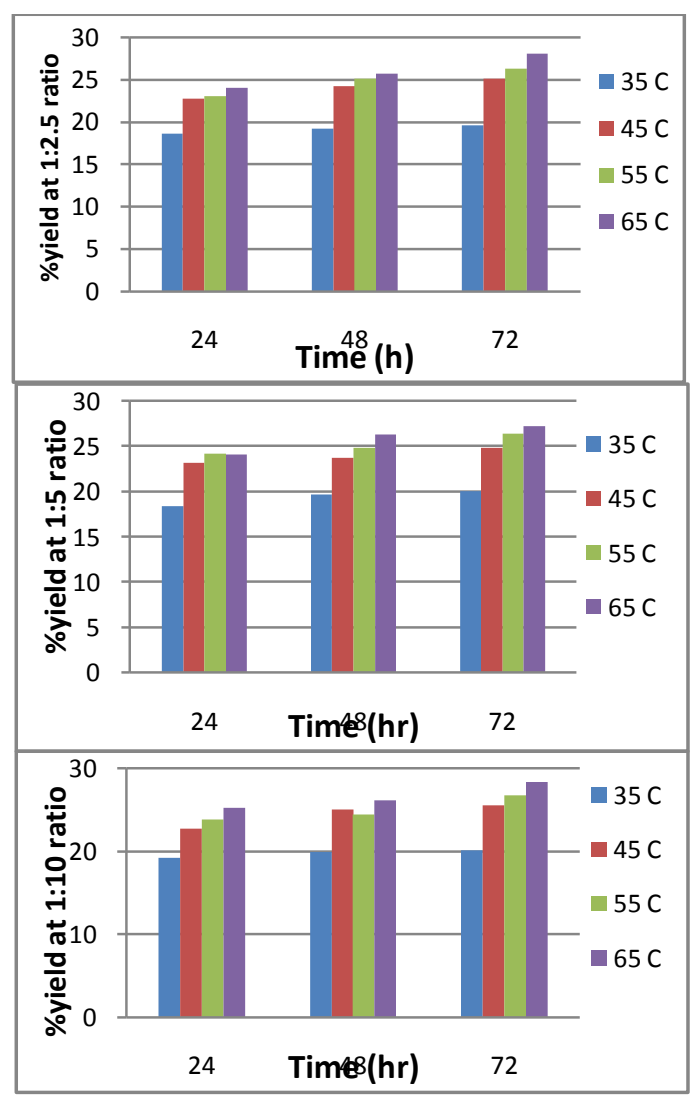

Fig. 2. Effect of temperature on percent yield of Moringa leaf extract at different dried powdered leaves to extraction solvent ratio.

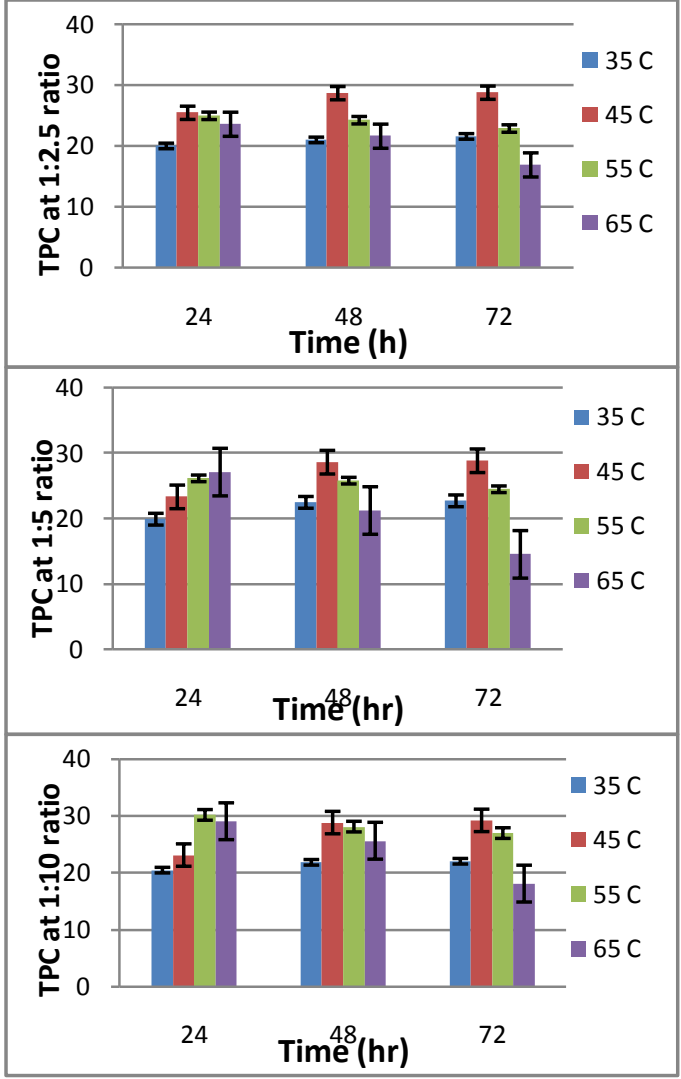

Fig. 3. Effect of temperature on TPC (g GAE/100 g extract) of Moringa leaf extract at different dried powdered leaves to extraction solvent ratio. 


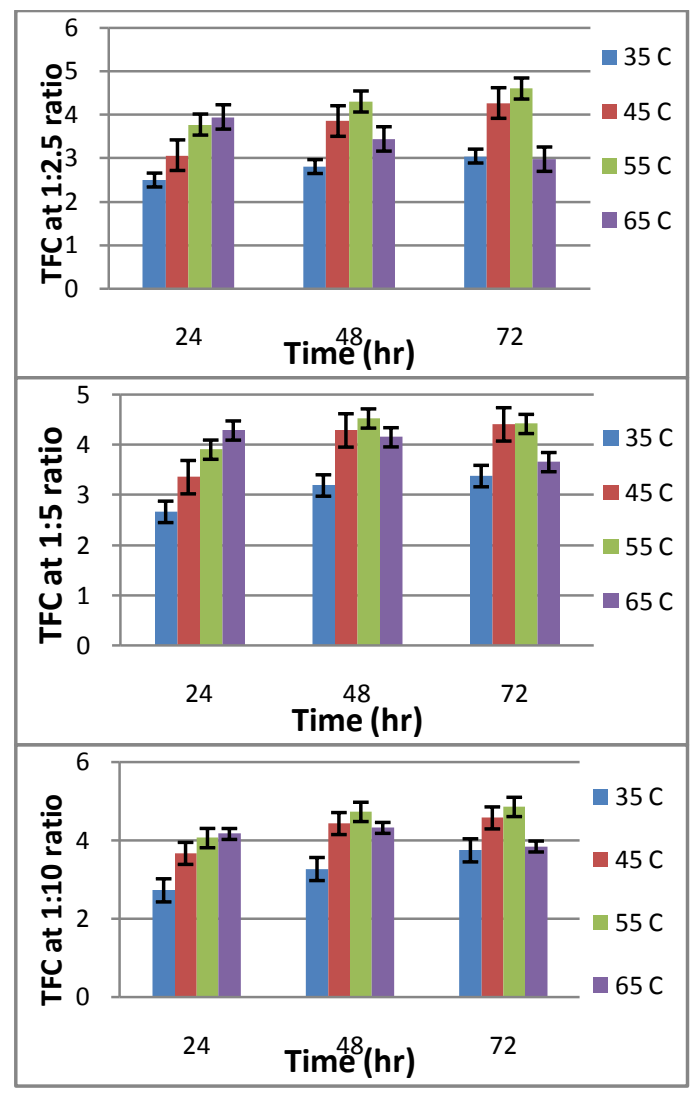

Fig. 4. Effect of temperature on TFC (g QE/100 $\mathrm{g}$ extract) of Moringa leaf extract at different dried powdered leaves to extraction solvent ratio.

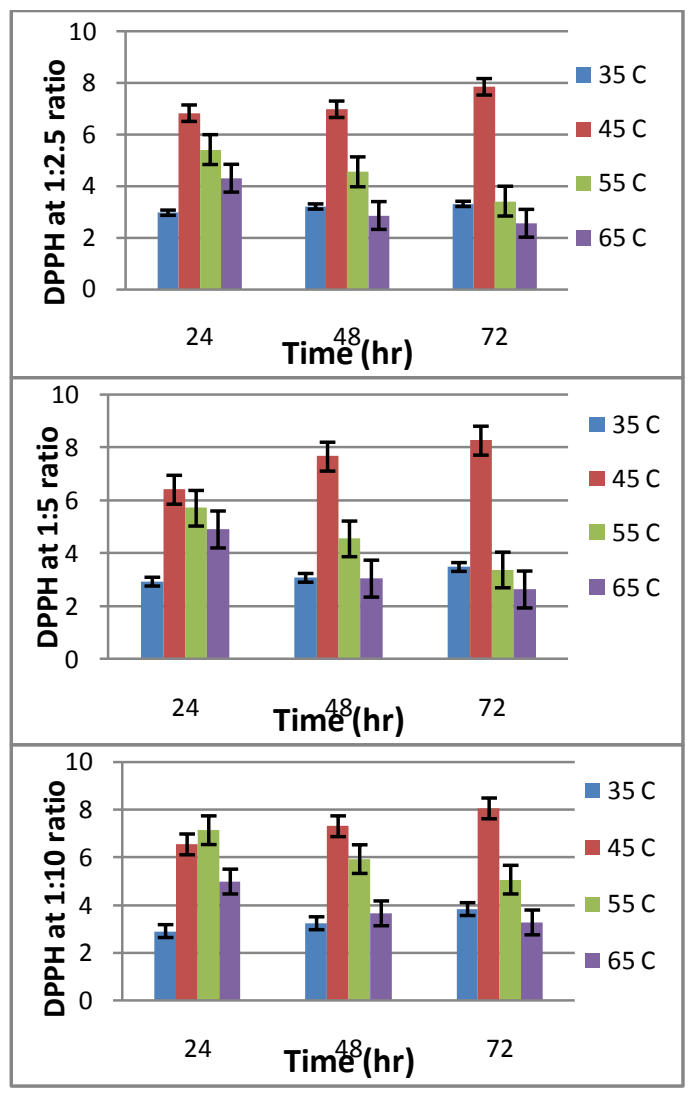

Fig. 5. Effect of temperature on DPPH (g AAE/100 g extract) of Moringa leaf extract at different dried powdered leaves to extraction solvent ratio.

Effects of maceration time on extract quantity and quality:-

The effect of maceration time on qualitative and quantitative parameters of the extract was directly interrelated to temperature of extraction. The maceration time has slight effect than temperature on $\%$ yield ( $p$ value 0.031 to 0.040), in that, at the same temperature of extraction as the maceration time increase the \% yield slightly increase (Fig. 6). A controversial effect of maceration time on TPC, TFC and total scavenging activity depending on temperature of extraction (Fig. 7, 8 and 9). An increase in TPC and total scavenging activity were noticed as the period of incubation increase at temperature of extraction 35 and $45^{\circ} \mathrm{C}$ and start to decrease as period of incubation increase at temperature of incubation 55 and $65^{\circ} \mathrm{C}$. For TFC the situation was different, an increase in TFC as period of incubation increase at temperature of extraction 35,45 and $55^{\circ} \mathrm{C}$ and start to decrease as period of incubation increase at temperature $65^{\circ} \mathrm{C}$. This may be because flavonoids are more heat stable than phenolics compounds (Ross et al., 2011; Sharma et al., 2015). The results clearly pointed that the selection of maceration time of extraction was depending on temperature of extraction. For instance, as the suggested temperature of extraction of Moringa dry leaf was $45^{\circ} \mathrm{C}$, the suggested maceration time is 48 or $72 \mathrm{~h}$ according to ratio of dried powdered leaves to extraction solvent to be use. 


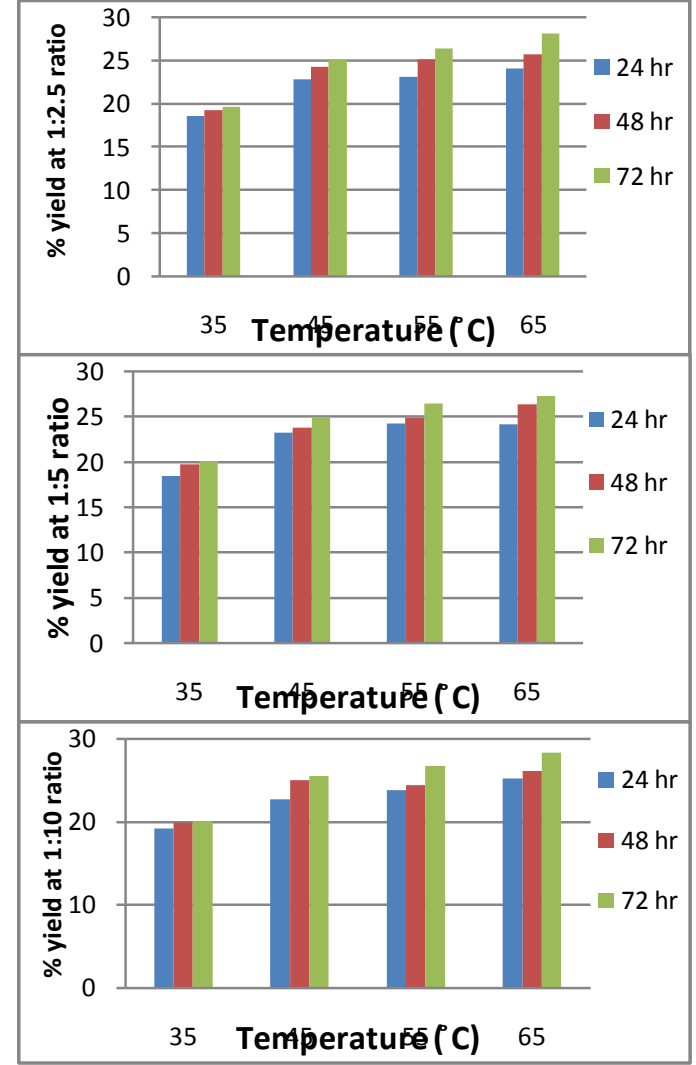

Fig. 6. Effect of maceration time on \% yield of Moringa leaf extract at different dried powdered leaves to extraction solvent ratio.

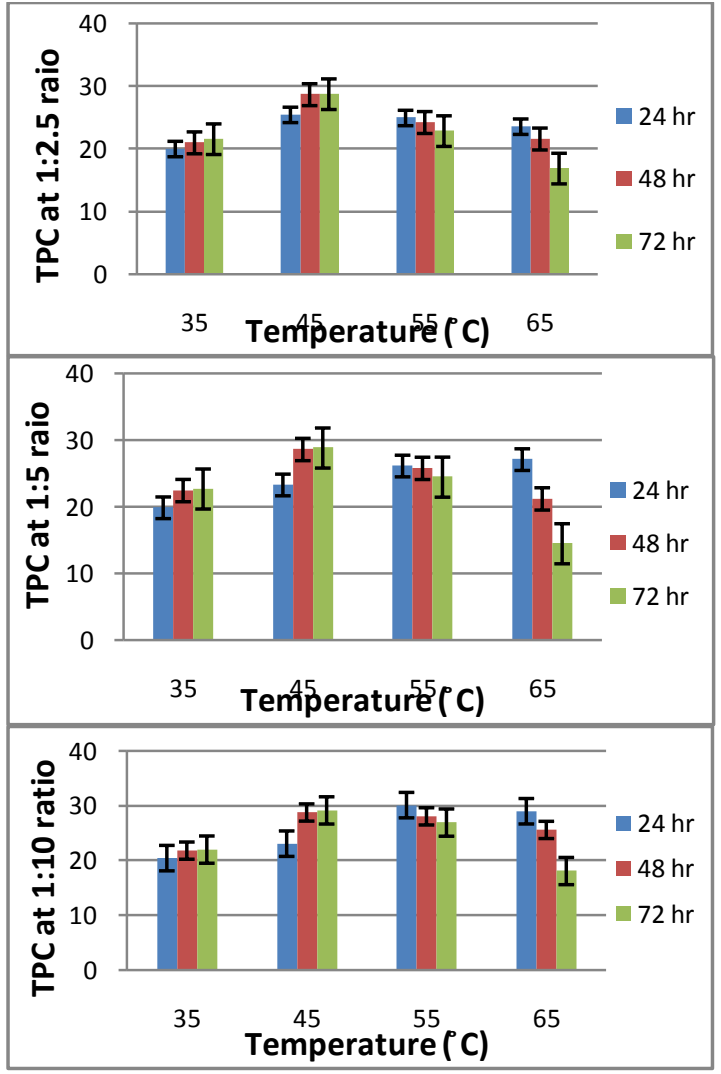

Fig. 7. Effect of maceration time on TPC (g GAE/100 g extract) of Moringa leaf extract at different dried powdered leaves to extraction 


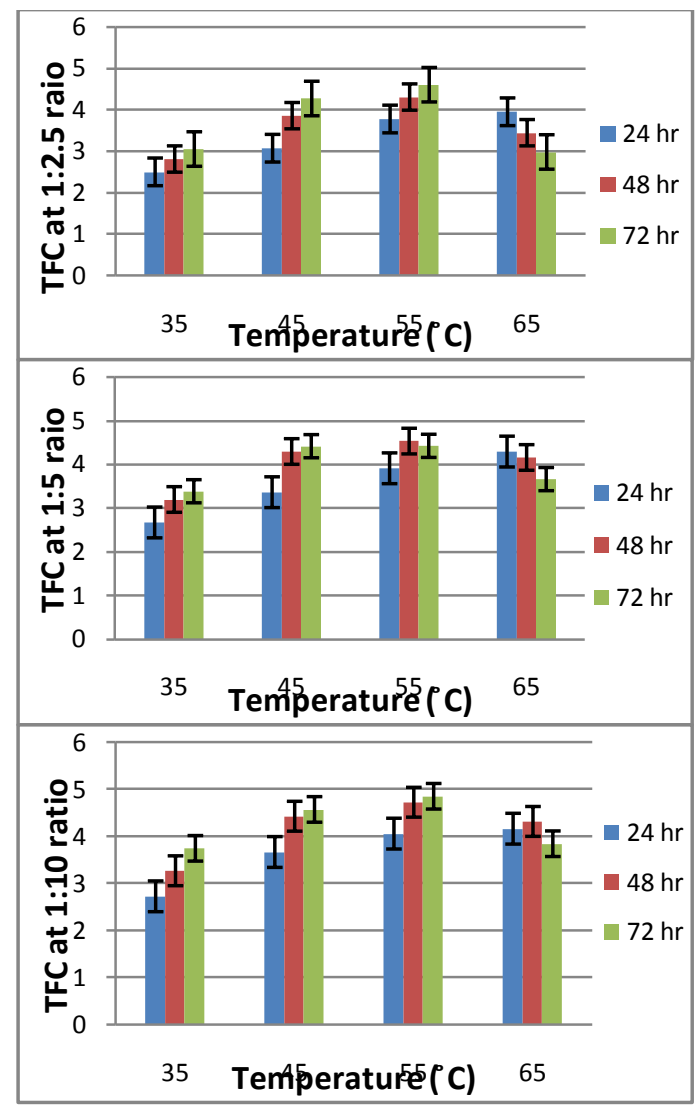

Fig. 8. Effect of maceration time on TFC (g $\mathrm{QE} / 100 \mathrm{~g}$ extract of Moringa leaves extract at different dried powdered leaves to extraction solvent ratio.

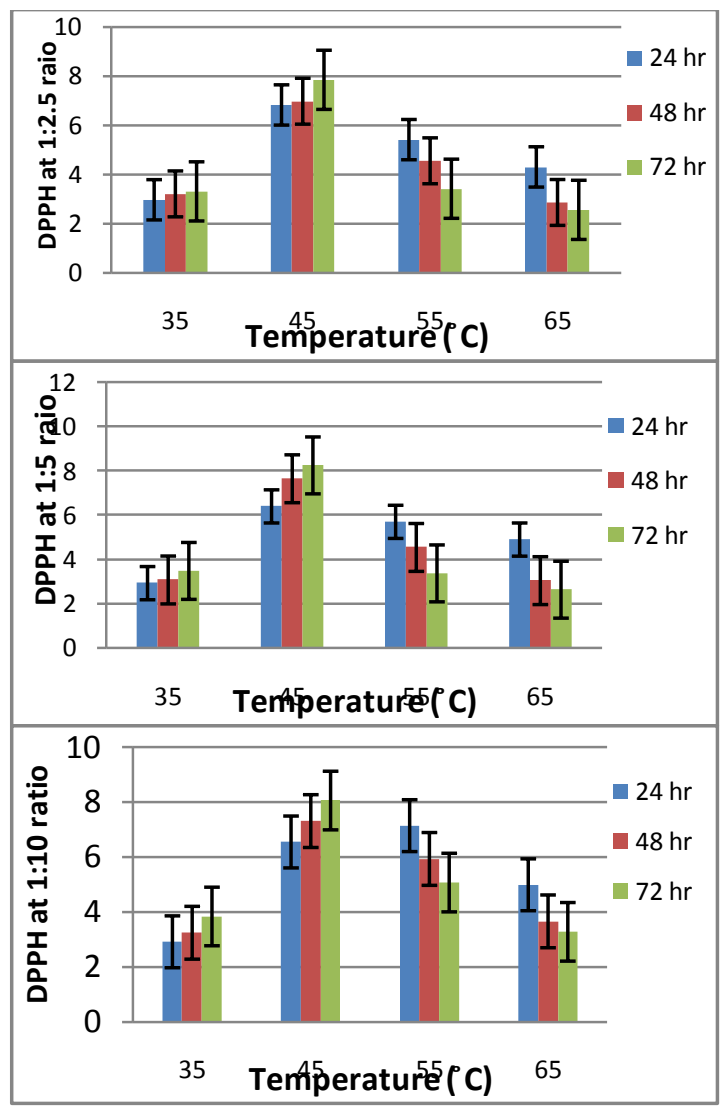

Fig. 9. Effect of maceration time on DPPH (g AAE/100g extract of Moringa leaves extract at different dried powdered leaves to extraction solvent ratio. 


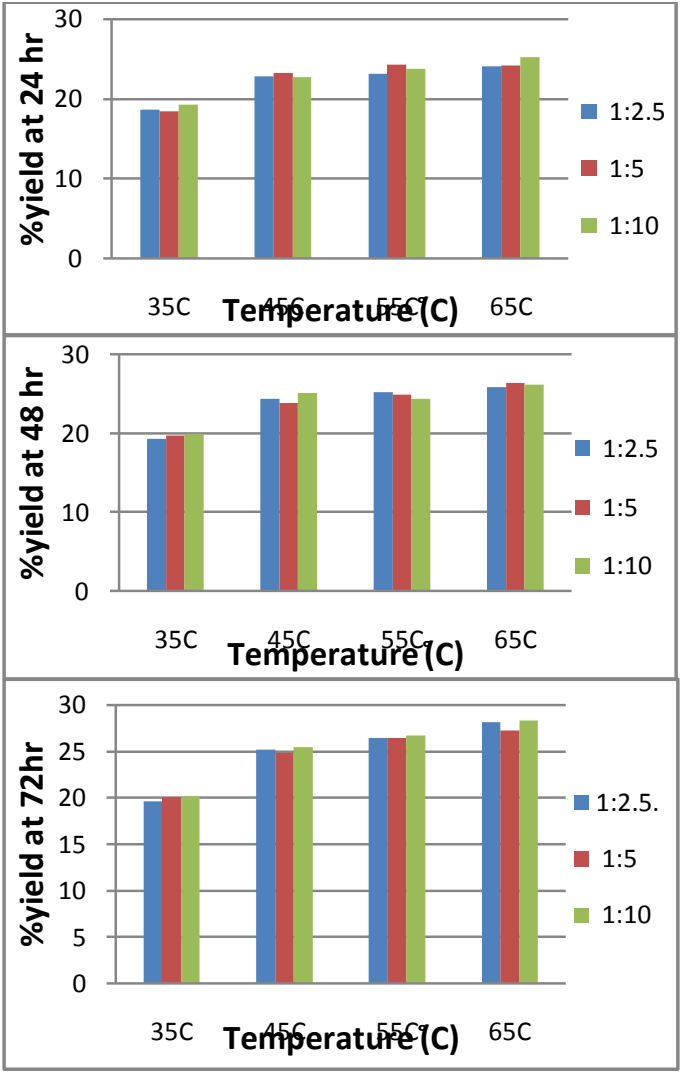

Fig. 10. Effect of dried powdered leaves to extraction solvent ratio on percent yield of Moringa leaf extract at different maceration time and temperature.

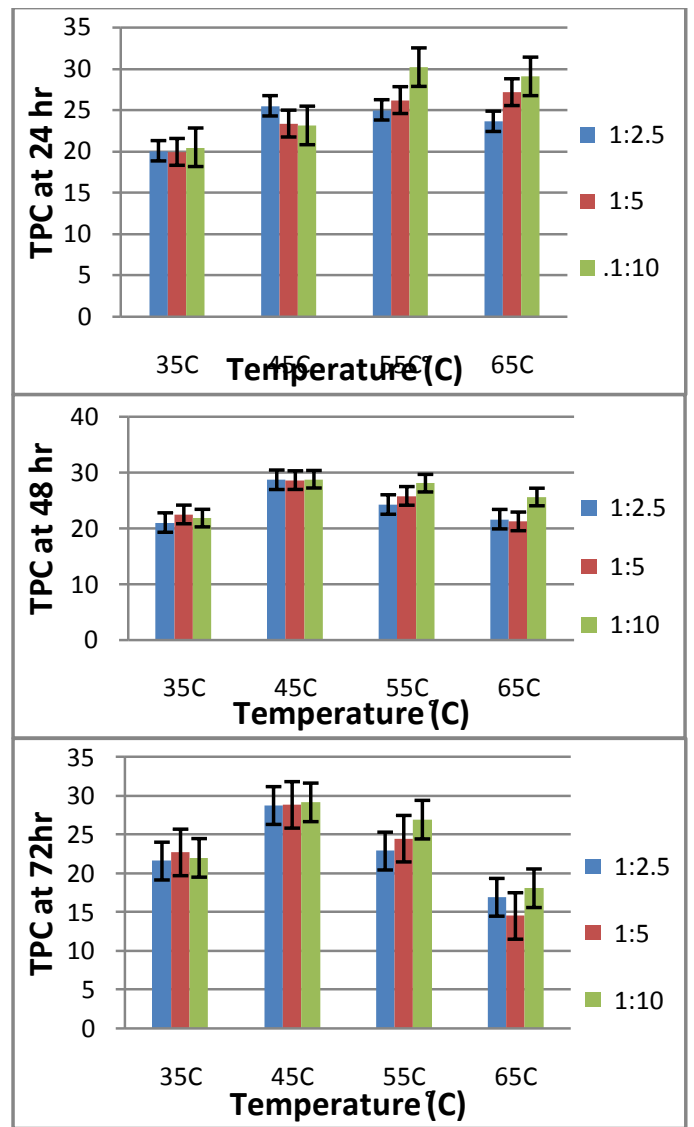

Fig. 11. Effect of dried powdered leaves to extraction solventratio on TPC of Moringa leaf extract at different maceration time and temperature. 


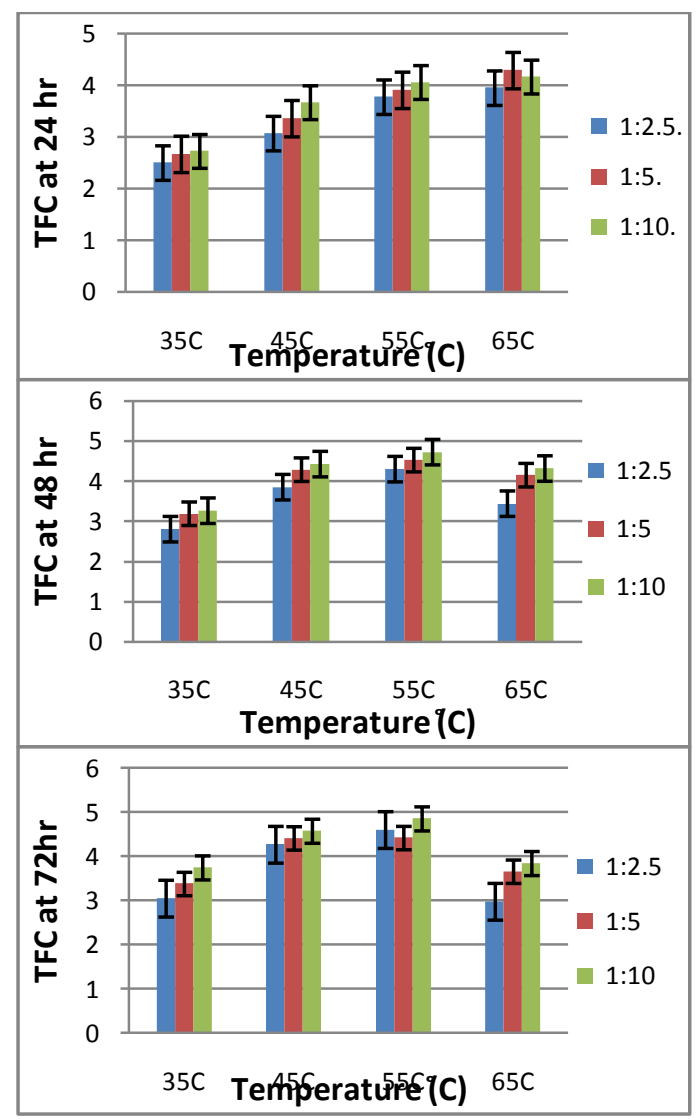

Fig. 12. Effect of dried powdered leaves to extraction solvent ratio on TPC of Moringa leaf extract at different maceration time and temperature.

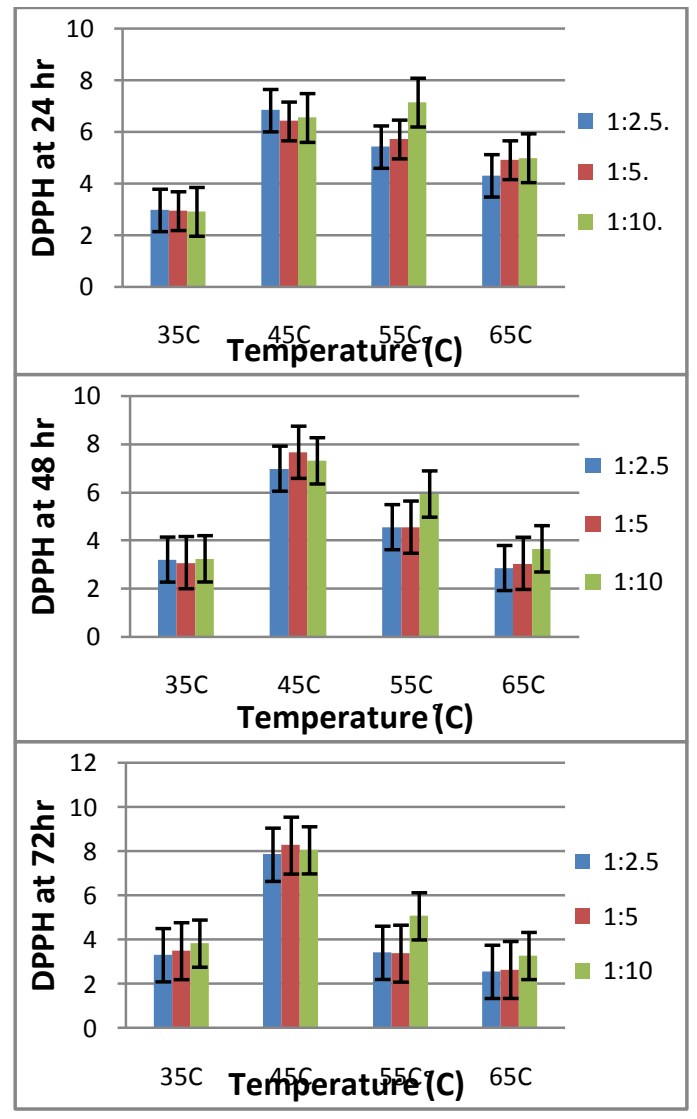

Fig. 13. Effect of dried powdered leaves to extraction solventratio on TPC of Moringa leaf extract at different maceration time and temperature.

Effects of dried powdered leaves to extraction solvent ratio on extract quantity and quality:-

At same extraction temperature and incubation period, dried powdered leaves to extraction solvent ratio has nonsignificant effect on quality and quantity of extract ( $p$ value 0.315 to 0.909 ). Dried powdered leaves to extraction solvent ratio shows a negligible effect on percent yield and a very slight effect on TPC and total scavenging activity ( $p$ value 0.046 to 0.969 ). On the other hand, an increase in dried powdered leaves to extraction solvent ratio shows little increase TFC; this may be due to higher solubility of phenolics compounds in ethanol more than flavonoids, so, increase in solvent volume lead to solubilization of more flavonoids (Medini et al., 2014). In addition to that, the solubility of flavonoids depend largely on whether they occur bounded to one or more sugar moiety (which become more polar) or as free form in which they are much less polar (Bohm, 1998). So, a more aggressive conditions and solvent volume are required to dissolve flavonoids in ethanol.

\section{Discussion:-}

Extraction was the most essential and critical step in a process of preparing high quality plant extract. In spite of immemorial and wide spread use of extraction procedure, it still need to be optimize according to type of plant, part of plant to be use, nature of targeted compounds and many other issues. Without doubt the quality and quantity of extract is highly effected by extraction conditions. In this study, the effects of type of extraction solvent, temperature of extraction, maceration time and dried powdered leaves to extraction solvent ratio on quantity and quality of Moringa leaf extract were evaluated by measuring percent yield, TPC, TFC and total scavenging activity in an attempt to determine best extraction condition. The high yields of water and $50 \%$ ethanol extraction solvents were attributed to high content of carbohydrates, electrolytes, amino acids, proteins, polysaccharides and other hydrophilic nutrients which are insoluble or slightly soluble in ethanol. Analysis of the results obviously revealed that $95 \%$ ethanol, as extraction solvent, extracted higher quantity of phenolics and flavonoids compounds than other solvents which coordinate with finding of other researchers (Luqman et al., 2011). Vongsak et al. 2013 shown 
almost the same percent yield of $38.34 \pm 1.17$ for dried Moringa leaf extracted by maceration in $50 \%$ ethanol for $72 \mathrm{~h}$ at room temperature and 1:40 dried powdered leaves to extraction solvent ratio. Jaiswal et al. 2009 shown a percent yield of $11.7 \%$ for aqueous extract by maceration in distilled water for $48 \mathrm{~h}$ at $60-70^{\circ} \mathrm{C}$ then filtered and dried first by rotary evaporator then by freeze dryer. The temperature of extraction was significantly effects on both quantity and quality of extract and directly correlated to maceration time. The increased extraction yield as the temperature of extraction increased may be because $M$. oleifera leaf contains large quantity of polysaccharides, carbohydrates and water soluble vitamins and minerals (Nouman et al., 2016) that slightly dissolve in ethanol and need higher temperature to enhance the solubility of such constituents. In addition to that, plant cell wall consider to be rigid, due to presence of cellulose, and need more vigorous conditions to be broken and release of cell contents. The effects of temperature on TPC reflects the sensitivity of phenolics compounds to long exposure to temperature higher than $55^{\circ} \mathrm{C}$ which lead to decomposition. A slight effect of maceration time on quantity of extract was detected within the same temperature of extraction. On the other hand, a noticeably effect of maceration time on quality of extract was detected within the same temperature of extraction. The effects of dried powdered leaves to extraction solvent ratio was found to be minor and irregular with no clear relation to temperature or maceration time. For high quality of $M$. oleifera leaf extract, a suggested extraction conditions of $72 \mathrm{~h}$ maceration time, $45^{\circ} \mathrm{C}$ extraction temperature and 1:2.5 ratio; $48 \mathrm{~h}$ maceration time, $45^{\circ} \mathrm{C}$ extraction temperature and $1: 5$ ratio or $24 \mathrm{~h}$ maceration time, $55^{\circ} \mathrm{C}$ extraction temperature and 1:10 ratio. one of the above mentioned set of extraction conditions best to be use with recommendation of selecting an amiable extraction condition for higher quality extract.

\section{Acknowledgment:-}

The authors would like to express their thankful to Discipline of Pharmaceutical Chemistry, School of Pharmaceutical Sciences, University of Sains Malaysia for supporting and providing necessary chemicals and equipments.

\section{References:-}

1. Agbogidi, O., and Ilondu, E. (2012): Moringa oleifera Lam: Its potentials as a food security and rural medicinal item. J Bio Innov, 1(6): 156-167.

2. Al-Owaisi, M., Al-Hadiwi, N., and Khan, S. A. (2014): GC-MS analysis, determination of total phenolics, flavonoid content and free radical scavenging activities of various crude extracts of Moringa peregrina (Forssk.) Fiori leaves. Asian Pac J Trop Biomed, 4(12): 964-970.

3. Arora, S., and Kaur, P. (2013): Preparation and characterization of phytosomal-phospholipid complex of p. amarus and its tablet formulation. J PharmTech, Res Manag, 1: 1 - 18.

4. Bhagyasri, Y., Lavakumar, V., DivyaSree, M., and Ashok Kumar, C. (2015): An overview on antiinflammatory activity of Indian herbal plan-ts. Int J Res Pharmaceut Nano Sci, 4: 1-9.

5. Bohm, B. A. (1998): Introduction to flavonoids. Amsterdam, Netherlands Harwood academic publishers, pp. $15-18$.

6. Coppin, J. P., Xu, Y., Chen, H., Pan, M.-H., Ho, C.-T., Juliani, R., and Wu, Q. (2013). Determination of flavonoids by LC/MS and anti-inflammatory activity in Moringa oleifera. J Funcl Foods, 5(4): 1892-1899.

7. Dent, M., Dragovic-Uzelac, V., Penic, M., Brncic, M., Bosiljkov, T., and Levaj, B. (2013): The effect of extraction solvents, temperature and time on the composition and mass fraction of polyphenols in Dalmatian wild sage (salvia officinalis L.) extracts. Food tech biotech, 51(1): 84.

8. Do, Q. D., Angkawijaya, A. E., Tran-Nguyen, P. L., Huynh, L. H., Soetaredjo, F. E., Ismadji, S., and Ju, Y.-H. (2014): Effect of extraction solvent on total phenol content, total flavonoid content, and antioxidant activity of Limnophila aromatica. J food drug anal, 22(3): 296-302.

9. Ganatra, T., Joshi, U., Bhalodia, P., Desai, T., and Tirgar, P. (2012): A panoramic view on pharmacognostic, pharmacological, nutritional, therapeutic and prophylactic values of Moringa oleifera lam. Int Res J Pharm, 3: $1-7$.

10. Gopalakrishnan, L., Doriya, K., and Kumar, D. S. (2016): Moringa oleifera: A review on nutritive importance and its medicinal application. Food Sci Hum Well, 5(2): 49-56.

11. Gullberg, J., Jonsson, P., Nordström, A., Sjöström, M., and Moritz, T. (2004): Design of experiments: an efficient strategy to identify factors influencing extraction and derivatization of Arabidopsis thaliana samples in metabolomic studies with gas chromatography/mass spectrometry. Anal biochem, 331(2): 283-295.

12. Isitua, C. C., Lozano, M. J. S.-M., and Jaramillo, C. (2015): Phytochemical and nutritional properties of dried leaf powder of Moringa oleifera Lam. from machala el oro province of ecuador. Asian J Plant Sci Res, 5(2): 816. 
13. Jaiswal, D., Rai, P. K., Kumar, A., Mehta, S., and Watal, G. (2009): Effect of Moringa oleifera Lam. leaves aqueous extract therapy on hyperglycemic rats. J Ethnopharmacol, 123(3): 392-396.

14. Jayanthi, M., Garg, S. K., Yadav, P., Bhatia, A., and Goel, A. (2015): Some newer marker phytoconstituents in methanolic extract of Moringa oleifera leaves and evaluation of its immunomodulatory and splenocytes proliferation potential in rats. Ind J pharmacol, 47(5), 518.

15. Jung, I. L. (2014): Soluble extract from Moringa oleifera leaves with a new anticancer activity. PloS one, 9(4): e95492.

16. Kesharwani, S., Prasad, P., Roy, A., and Sahu, R. K. (2014): An overview on phytochemistry and pharmacological explorations of moringa oleifera. UK J Pharm Biosci, 2(1): 34-41.

17. Kumar, S., Prasad, A., Iyer, S., and Vaidya, S. (2013): Systematic pharmacognostical, phytochemical and pharmacological review on an ethno medicinal plant, Basella alba L. J Pharmacogn Phytotherapy, 5(4): 53-58.

18. Kumar, V., Verma, A., Ahmed, D., Sachan, N. K., Anwar, F., and Mujeeb, M. (2013): Fostered antiarthritic upshot of moringa oleifera lam. stem bark extract in diversely induced arthritis in wistar rats with plausible mechanism. Int J Pharm Sci Res, 4(10): 3894.

19. Leone, A., Spada, A., Battezzati, A., Schiraldi, A., Aristil, J., and Bertoli, S. (2015): Cultivation, genetic, ethnopharmacology, phytochemistry and pharmacology of Moringa oleifera leaves: An overview. Int J Mol Sci, 16(6): 12791-12835.

20. Luqman, S., Srivastava, S., Kumar, R., Maurya, A. K., and Chanda, D. (2011): Experimental assessment of Moringa oleifera leaf and fruit for its antistress, antioxidant, and scavenging potential using in vitro and in vivo assays. J Evid Based Complementary Altern Med, 2012: 12.doi: doi:10.1155/2012/519084

21. Maheshwari, R. K., Jat, B. L., Chaudhary, K., and Verma, N. (2014): Legitimacy \& Awesomeness of Drumstick tree (Moringa oleifera Lam.) for Healthcare \& Socio-economic Perspective. Int J Pharm, 2(12): 1420 $-1430$.

22. Medini, F., Fellah, H., Ksouri, R., and Abdelly, C. (2014): Total phenolic, flavonoid and tannin contents and antioxidant and antimicrobial activities of organic extracts of shoots of the plant Limonium delicatulum. $\mathrm{J}$ Taibah Univer Sci, 8(3): 216-224.

23. Muazu, J., and Suleiman, Z. (2014): Design, Formulation and Tableting Properties of Aqueous Leaf Extract of Moringa oleifera. Br J Pharm Res, 4(19): 2261.

24. Nath, I., Paul, S., and Nath, B. (2015): Moringa oleifera: bio-inspired approaches to plant based nanomedicine, a mini review. Europ J Mol Biol Biochem, 2(5): 186 - 189.

25. Nouman, W., Anwar, F., Gull, T., Newton, A., Rosa, E., and Domínguez-Perles, R. (2016): Profiling of polyphenolics, nutrients and antioxidant potential of germplasm's leaves from seven cultivars of Moringa oleifera Lam. Ind Crops Prod, 83: 166-176.

26. Pyrzynska, K., and Pękal, A. (2013): Application of free radical diphenylpicrylhydrazyl (DPPH) to estimate the antioxidant capacity of food samples. Anal Methods, 5(17): 4288-4295.

27. Ross, C. F., Hoye Jr, C., and Fernandez- Plotka, V. C. (2011): Influence of heating on the polyphenolic content and antioxidant activity of grape seed flour. J Food Sci, 76(6): C884-C890.

28. Ruenroengklin, N., Zhong, J., Duan, X., Yang, B., Li, J., and Jiang, Y. (2008): Effects of various temperatures and $\mathrm{pH}$ values on the extraction yield of phenolics from litchi fruit pericarp tissue and the antioxidant activity of the extracted anthocyanins. Int J Mol Sci, 9(7): 1333-1341.

29. Sankhalkar, S., and Vernekar, V. (2016): Quantitative and Qualitative analysis of Phenolic and Flavonoid content in Moringa oleifera Lam and Ocimum tenuiflorum L. Pharmacogn Res, 8(1): 16.

30. Sharma, K., Ko, E. Y., Assefa, A. D., Ha, S., Nile, S. H., Lee, E. T., and Park, S. W. (2015): Temperaturedependent studies on the total phenolics, flavonoids, antioxidant activities, and sugar content in six onion varieties. J Food Drug Anal, 23: 243-252.

31. Tan, M. C., Tan, C. P., and Ho, C. (2013): Effects of extraction solvent system, time and temperature on total phenolic content of henna (Lawsonia inermis) stems. Int Food Res J, 20(6): 3117-3123.

32. Varma, N. (2016): Phytoconstituents and Their Mode of Extractions: An Overview. Res J. Chem. Environ. Sci., 4(2): $8-15$.

33. Vongsak, B., Sithisarn, P., Mangmool, S., Thongpraditchote, S., Wongkrajang, Y., and Gritsanapan, W. (2013): Maximizing total phenolics, total flavonoids contents and antioxidant activity of Moringa oleifera leaf extract by the appropriate extraction method. Ind Crops Prod, 44: 566-571.

34. Zaku, S., Emmanuel, S., Tukur, A., and Kabir, A. (2015): Moringa oleifera: An underutilized tree in Nigeria with amazing versatility: A review. African J Food Sci, 9(9): 456-461. 